\title{
Development and demonstration of a new SANEX Partitioning Process for selective actinide(III)/lanthanide(III) separation using a mixture of $\mathrm{CyMe}_{4} \mathrm{BTBP}$ and TODGA
}

\author{
By G. Modolo ${ }^{1, *}$, A. Wilden ${ }^{1}$, H. Daniels ${ }^{1}$, A. Geist ${ }^{2}$, D. Magnusson ${ }^{2}$ and R. Malmbeck ${ }^{3}$ \\ ${ }^{1}$ Forschungszentrum Jülich GmbH, Institut für Energie- und Klimaforschung - Nukleare Entsorgung und Reaktorsicherheit - (IEK-6), \\ 52425 Jülich, Germany \\ 2 Karlsruher Institut für Technologie, Institut für Nukleare Entsorgung, 76021 Karlsruhe, Germany \\ ${ }^{3}$ European Commission, JRC, Institute for Transuranium Elements (ITU), 76125 Karlsruhe, Germany
}

(Received March 9, 2012; accepted in final form August 3, 2012)

(Published online January 28, 2013)

\section{SANEX / Minor actinides / Americium / Curium / Partitioning / TODGA / $\mathrm{CyMe}_{4} \mathrm{BTBP}$}

\begin{abstract}
Summary. Within the framework of the European collaborative project ACSEPT, a new SANEX partitioning process was developed at Forschungszentrum Jülich for the separation of the trivalent minor actinides americium, curium and californium from lanthanide fission products in spent nuclear fuels. The development is based on batch solvent extraction studies, singlecentrifugal contactor tests and on flow-sheet design by computer code calculations. The used solvent is composed of 6,6'-bis(5,5,8,8-tetramethyl-5,6,7,8-tetrahydrobenzo[1,2-4]trizazin-3-yl)-[2,2']-bipyridine $\quad\left(\mathrm{CyMe}_{4} \mathrm{BTBP}\right)$ and $N, N, N^{\prime}, N^{\prime}$-tetraoctyldiglycolamide (TODGA) dissolved in $n$ octanol. A spiked continuous counter-current test was carried out in miniature centrifugal contactors with the aid of a 20stage flow-sheet consisting of 12 extraction, 4 scrubbing and 4 stripping stages. A product fraction containing more than $99.9 \%$ of the trivalent actinides Am(III), Cm(III) and $\mathrm{Cf}(\mathrm{III})$ was obtained. High product/feed decontamination factors $>1000$ were achieved for these actinides. The trivalent lanthanides were directed to the raffinate of the process with the actinide (III) product stream being contaminated with less than 0.5 mass- $\%$ of the initial lanthanides.
\end{abstract}

\section{Introduction}

The selective partitioning of minor actinides (MAs: Am, $\mathrm{Cm}$, Cf) from fission products and separate treatment by transmutation can considerably improve the long-term safety of nuclear waste by reducing the long-term radiotoxicity. Several processes have been developed for the recovery of americium and curium from the PUREX waste stream containing lanthanides and other fission products [1]. European research over the last decade, i.e. in the NEWPART [2], PARTNEW [3] and EUROPART [4] programmes, has resulted in the development of a combined DIAMEX and SANEX process [3,5]. The DIAMEX

\footnotetext{
*Author for correspondence (E-mail: G.Modolo@fz-juelich.de).
}

and SANEX process and other multi-cycle processes are based on the co-separation of trivalent actinides and lanthanides from the non-lanthanide fission- and activation products (e.g. by the DIAMEX [6], TODGA/TBP [7, 8] or T2EHDGA-based $[9,10]$ processes), followed by the subsequent actinide(III)/lanthanide(III) group separation (e.g. the SANEX process) [11].

In the context of any actinide transmutation strategy, the separation of trivalent actinides (americium and curium, also californium at higher burn-ups) from lanthanides is a key step [12]. The large neutron capture cross-sections of some lanthanide isotopes would disturb the neutron balance of a transmutation reaction and thereby hinder the efficient transmutation of the minor actinides. Unfortunately, the separation of trivalent minor actinides and lanthanides still causes considerable problems due to the chemical similarity of the two groups of elements. The required decontamination factors (DF) should therefore be considered from the viewpoint of neutron absorption cross section of the lanthanides and of possible interactions of the lanthanides within the host phase of a transmutation target/fuel material.

Since the early 1980s, considerable efforts have been devoted worldwide to develop efficient An(III)/Ln(III) separations by solvent extraction processes which rely upon the slightly higher affinity of trivalent actinides towards soft donor ligands containing sulphur- or nitrogen-bearing groups [13-19].

Among the various nitrogen based ligands that have been shown to be able to extract trivalent actinides selectively over trivalent lanthanides from highly acidic media $\left(\mathrm{HNO}_{3}>1 \mathrm{~mol} / \mathrm{L}\right)$ are the 2,6-bis-(5,6-dialkyl-1,2,4triazin-3-yl)-pyridines (known as BTPs), discovered first by Kolarik et al. from the INE laboratory at KIT Karlsruhe during the NEWPART EU-project [5, 20].

Counter-current SANEX tests with genuine highly active feed solutions have shown promising results, but a major drawback is the low stability of the organic extractant against hydrolysis and radiolysis [21]. Therefore, the BTP molecules were further developed at the University of Reading, UK, in order to increase the chemical stability of the 
<smiles>CC1(C)CCC(C)(C)c2nc(-c3cccc(-c4cccc(-c5nnc6c(n5)C(C)(C)CCC6(C)C)n4)n3)nnc21</smiles>

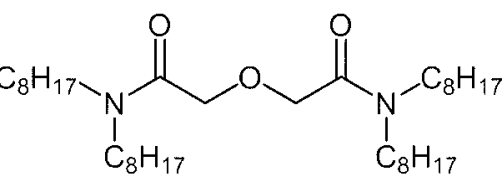

Fig. 1. $\mathrm{CyMe}_{4} \mathrm{BTBP}$ and TODGA used in the SANEX process. ligands towards hydrolysis and radiolysis as well as to improve the ability to strip the extracted metals. This was achieved by adding one more pyridine ring to the backbone of the BTP molecules, which produced the BTBP class ligands (see Fig. 1). The $\mathrm{CyMe}_{4} \mathrm{BTBP}$ molecule was introduced as a potential SANEX extractant for the separation of actinides(III) from lanthanides(III) [22]. Unfortunately, the extraction and stripping kinetics were shown to be rather slow and a phase transfer reagent, such as a malonamide (e.g. DMDOHEMA [ $N, N^{\prime}$-dimethyl- $N, N^{\prime}$-dioctyl-2(2-(hexyloxy)ethyl)-malonamide]), was added for the development of a reversible extraction process [23].

Within the framework of the process-orientated work at Forschungszentrum Jülich, an alternative process was developed using the diglycolamide TODGA (Fig. 1) as phase transfer reagent. Since TODGA itself is a very efficient but non-selective extractant for the co-extraction of actinides(III) and lanthanides(III) [24], only small concentrations of TODGA were used for the optimization of the formulation of the SANEX process. Batch extraction and single centrifugal contactor tests were carried out and the results were used to design a flow-sheet with the help of computer code calculations. The new SANEX process for actinide(III)/lanthanide(III) separation was tested in a miniature centrifugal contactor battery with the aid of a 20stage flow-sheet consisting of 12 extraction, 4 scrubbing and 4 stripping stages. In the present paper, the results of the demonstration of the SANEX process are presented and discussed.

\section{Modelling}

The concentration profiles were calculated using the SX Process program [25]. Eq. (1) is used in the program to express the mass transfer rate between the phases in the mixer part of a centrifugal contactor. The expression is based on mass balances at a fixed time in the mixer and is used to calculate the transfer over a small time step in the program. The program can calculate with constant distribution ratios or with the distribution ratio as a function of for example aqueous acidity.

$$
-\frac{\mathrm{d} n_{\mathrm{Aq}}}{\mathrm{d} t}=\frac{n_{\mathrm{Total}} \cdot V_{\mathrm{Aq}} \cdot V_{\mathrm{Org}} \cdot \frac{\mathrm{d} D}{\mathrm{~d} t}}{\left(V_{\mathrm{Aq}}+D \cdot V_{\mathrm{Org}}\right)^{2}}
$$

where $n_{\mathrm{Aq}}$ is the substance in the aqueous phase, $n_{\text {Total }}$ is the total substance in the mixing chamber, $D$ is the distribution ratio in the mixer, and $V$ are the aqueous and organic mixer volumes.

At every time step the total substance and volumes are known. The distribution ratio can be calculated from the concentrations in the aqueous and organic phases before the mass transfer, and only the derivative $\mathrm{d} D / \mathrm{d} t$ is unknown. Eq. (2) shows the expression for the derivative used in the program.

$$
\frac{\mathrm{d} D}{\mathrm{~d} t}=\frac{B \cdot\left(\frac{D_{\mathrm{Eq}}-D}{V_{\mathrm{Aq}}+D \cdot V_{\mathrm{Org}}}\right) \cdot\left(V_{\mathrm{Aq}}+D_{\mathrm{Eq}} \cdot V_{\mathrm{Org}}\right)}{\left(1+\frac{V_{\mathrm{Org}} \cdot\left(D_{\mathrm{Eq}}-D\right)}{V_{\mathrm{Aq}}+D \cdot V_{\mathrm{Org}}}\right)^{2}}
$$

where $B$ is the transfer rate constant and $D_{\mathrm{Eq}}$ is the equilibrium distribution ratio.

For Eq. (2), $D_{\mathrm{Eq}}$ and $B$ have to be determined experimentally. The equilibrium distribution ratio is determined by batch experiments. The transfer rate constant can be achieved by running kinetics experiments where the distribution ratio is measured after certain mixer times, as shown in Ref. [25]. In this case such data was not available but instead single stage centrifugal contactor data was used. The calculations are done here first for a single stage and $B$ is changed until the calculated distribution ratio agrees with the experimental value. The same $B$ value is then used in the program for the complete process calculations. Single stage data is needed for every section in the process since the $B$ varies a lot if the conditions in the centrifugal contactor are changed, such as the acidity, flow rates, extraction or back extraction, etc. The $D_{\mathrm{Eq}}$ should be measured under the same conditions as the single stage experiment is carried out.

\section{Experimental}

$\mathrm{CyMe}_{4} \mathrm{BTBP}$ was synthesized and provided by Reading University, UK. Details of synthesis, stability and general extraction properties can be found in Ref. [23]. TODGA was synthesized in our labs according to a known synthesis route based on diglycolyl chloride and dioctylamine as starting materials [7]. The extractant mixture was prepared by dissolving appropriate amounts of $\mathrm{CyMe}_{4} \mathrm{BTBP}$ and TODGA in $n$-octanol to obtain the final concentrations of $0.015 \mathrm{~mol} / \mathrm{L} \mathrm{CyMe} \mathrm{CHTB}_{4}$ and $0.005 \mathrm{~mol} / \mathrm{L}$ TODGA. The An(III)/Ln(III) feed was a synthetic solution of lanthanides with the lanthanide concentrations corresponding to a real TODGA/TBP process product solution $[8,26]$, spiked with trace amounts of the tracers ${ }^{241} \mathrm{Am},{ }^{244} \mathrm{Cm},{ }^{252} \mathrm{Cf}$ and ${ }^{152} \mathrm{Eu}$ which were supplied by Isotopendienst M. Blaseg GmbH, Waldburg, Germany and Eckert \& Ziegler Nuclitec $\mathrm{GmbH}$, Braunschweig, Germany. The composition of the feed solution is shown in Table $1 . \mathrm{Np}$ and $\mathrm{Pu}$ were not included into the raffinate because these elements were also not studied in Refs. [8,26]. Nevertheless, it is planned to include them in future work, as a complete separation of these 
Table 1. Composition of the synthetic An(III)/Ln(III) feed used for the SANEX process.

\begin{tabular}{lcc}
\hline $\begin{array}{l}\text { Element or } \\
\text { material }\end{array}$ & $\begin{array}{c}\text { Concentration } \\
(\mathrm{mg} / \mathrm{L})\end{array}$ & $\begin{array}{c}\text { Nuclide/activity } \\
(\mathrm{MBq} / \mathrm{L})\end{array}$ \\
\hline $\mathrm{Y}$ & 55 & \\
$\mathrm{La}$ & 205 & \\
$\mathrm{Ce}$ & 383 & \\
$\mathrm{Pr}$ & 192 & \\
$\mathrm{Nd}$ & 716 & \\
$\mathrm{Sm}$ & 142 & \\
$\mathrm{Eu}$ & 129 & $\mathrm{Eu} / 3.3$ \\
$\mathrm{Gd}$ & 85 & ${ }^{241} \mathrm{Am} / 2.5$ \\
$\mathrm{Am}$ & traces & ${ }^{244} \mathrm{Cm} / 2.4$ \\
$\mathrm{Cm}$ & traces & \\
$\mathrm{Cf}$ & traces & \\
$\mathrm{HNO}_{3}$ & $1.3 \mathrm{Cf} / 1.6$ \\
\hline
\end{tabular}

elements in preceding processes cannot be assured. The behaviour of $\mathrm{Np}$ and $\mathrm{Pu}$ in the process should be clarified.

The feed acidity was adjusted to $1.3 \mathrm{~mol} / \mathrm{L} \mathrm{HNO}_{3}$, although a preceding TODGA/TBP process $[7,8,26]$ would deliver a product at lower $\mathrm{HNO}_{3}$ concentration. An acidity of $1.3 \mathrm{~mol} / \mathrm{L} \mathrm{HNO}_{3}$ is needed to get a good $\mathrm{Am}+$ $\mathrm{Cm}$ extraction in combination with high $\mathrm{An}(\mathrm{III}) / \mathrm{Ln}(\mathrm{III})$ separation factors. The conditions were elaborated in optimization studies (see results and discussion). Since the solvent mixture used in this study works even at higher

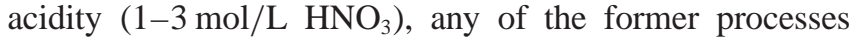
(TRUEX [27], DIAMEX [6]) delivering an An(III)/Ln(III) mixture can be used for the An/Ln co-separation without introducing a more complicated denitration head end step. Extraction at low acidity is in general more complicated due to the difficulty in controlling the $\mathrm{pH}$, without adding buffers.

The suggested SANEX process can work after DIAMEX or TRUEX, and it is quite easy to increase the acidity simply by adding the appropriate amount of $\mathrm{HNO}_{3}$ (no additional secondary waste).

An optimized 20-stage flow-sheet (Fig. 2) was designed by computer code calculations [28] using data from batch and single centrifuge experiments [29]. The obtained flowrates were $10 \mathrm{~mL} / \mathrm{h}$ for all fluxes used in the process. These flow-rates are quite low, but still applicable in a lab-scale miniature centrifugal contactor setup. Nevertheless, the presented process is a lab-scale process aiming at demonstrating the principle and feasibility of such a separation process.

\subsection{Batch extraction tests}

The batch extraction experiments were performed in $2 \mathrm{~mL}$ glass vials. $500 \mu \mathrm{L}$ organic and aqueous phases were spiked with $10 \mu \mathrm{L}$ radioactive tracer solution and equilibrated for $60 \mathrm{~min}$ by vigorous shaking in a vortex mixer. This contact time was sufficient to attain the distribution equilibrium. After phase separation by centrifugation, $200 \mu \mathrm{L}$ aliquots of each phase were withdrawn for radio analysis. Gammaanalysis was performed using a high-purity germanium spectrometer system purchased from EG\&G Ortec. The $\gamma$ lines at $59.5 \mathrm{keV}$ and $121.8 \mathrm{keV}$ were examined for ${ }^{241} \mathrm{Am}$ and ${ }^{152} \mathrm{Eu}$, respectively. ${ }^{241} \mathrm{Am},{ }^{244} \mathrm{Cm}$, and ${ }^{252} \mathrm{Cf}$ were measured by alpha spectrometry with an Alpha Spectrometer Octête $^{\mathrm{TM}}$ PC purchased from EG\&G Ortec, Munich, Germany. Stable elements were determined by ICP-MS on an Elan 6100 DRC from Perkin Elmer Sciex, Roggau-Jügesheim, Germany. The aqueous phase was directly measured after adequate dilution. The organic phase was analysed after microwave digestion.

The metal distribution ratios, $D$, were calculated as the ratio between the radioactivity or concentration of a radioisotope or element in the organic and the aqueous phase. Distribution ratios between 0.01 and 100 exhibit a maximum error of $\pm 5 \%$. The maximum and minimum distribution ratios arising from the detection limits in the aqueous and organic phases were 1000 and 0.001 , respectively.

\subsection{Single-centrifugal contactor experiments}

The experiments were performed in a single-stage centrifugal contactor setup, comprising a single $1 \mathrm{~cm}$ stainless steel centrifugal contactor (produced by INET, China) together with the contactor housing. Two syringe pumps were connected to the contactor and used to precisely pump the organic and aqueous solutions after prior calibration. The experimental conditions for the determination of the centrifuge efficiency during extraction, scrubbing and stripping are summarized in Table 2.

First, the extraction performance was tested. Attainment of the steady state (after approx. $30 \mathrm{~min}$ of operation) was checked by following the ${ }^{241} \mathrm{Am}$ and ${ }^{152} \mathrm{Eu}$ activities by $\gamma$ spectrometry. After extraction, the collected organic solution was used for scrubbing with $0.72 \mathrm{~mol} / \mathrm{L} \mathrm{HNO}_{3}$. Stripping was carried out using an aqueous solution of $0.5 \mathrm{~mol} / \mathrm{L}$ glycolic acid adjusted to $\mathrm{pH} 4$ using the collected organic solution after scrubbing. After each step, distribution ratios for each stage were also determined using the solutions taken

Table 2. Conditions for the determination of extraction, scrubbing, and stripping efficiencies of a single centrifugal contactor.

\begin{tabular}{|c|c|c|c|}
\hline Conditions & Organic phase & Aqueous phase & A/O flow-rates \\
\hline Extraction & $\begin{array}{l}0.015 \mathrm{~mol} / \mathrm{L} \mathrm{CyMe} \mathrm{CHTP}_{4} \mathrm{BBP} \\
+0.005 \mathrm{~mol} / \mathrm{L} \mathrm{TODGA} \\
\text { in } n \text {-octanol }\end{array}$ & $\begin{array}{l}c f . \text { Table } 1 \\
1.12 \mathrm{~mol} / \mathrm{L} \mathrm{HNO}_{3}\end{array}$ & $20 \mathrm{~mL} / \mathrm{h} / 10 \mathrm{~mL} / \mathrm{h}$ \\
\hline Scrubbing & $\begin{array}{l}\text { Loaded organic phase collected } \\
\text { from extraction }\end{array}$ & $0.72 \mathrm{~mol} / \mathrm{L} \mathrm{HNO}_{3}$ & $10 \mathrm{~mL} / \mathrm{h} / 10 \mathrm{~mL} / \mathrm{h}$ \\
\hline Stripping & $\begin{array}{l}\text { Loaded organic phase collected } \\
\text { from scrubbing }\end{array}$ & $\begin{array}{l}0.5 \mathrm{~mol} / \mathrm{L} \text { glycolic } \\
\text { acid, } \mathrm{pH} 4\end{array}$ & $10 \mathrm{~mL} / \mathrm{h} / 10 \mathrm{~mL} / \mathrm{h}$ \\
\hline
\end{tabular}




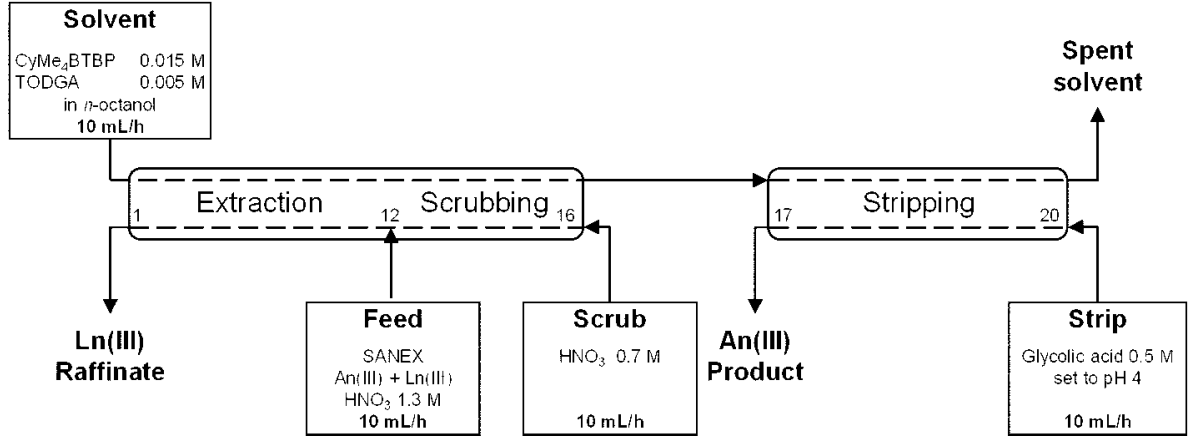

Fig. 2. Flow-sheet of the SANEX process using $\mathrm{CyMe}_{4} \mathrm{BTBP}+$ TODGA as extractants. from the wells after the contactor was completely emptied. Phase separation and analysis were performed as described above.

\subsection{Centrifugal contactor spiked multi-stage counter current test}

The SANEX test was carried out using a battery of miniature centrifugal contactors in a counter-current mode. Details of the experimental setup can be found in Ref. [7]. The pumps used in the test were piston pumps, which were able to produce small flow-rates controlled by weighing. Since only 16 stages were available, stripping was performed in a separate test with 4 stages after the apparatus had been cleaned. The solvent loaded with actinides(III) (coming from stage 16) was collected in 2 batches for this purpose and the fraction collected after the attainment of the steady state was used for stripping. The continuous process described in the following consists of three process sections:

- 12 extraction stages for the extraction of Am(III), $\mathrm{Cm}$ (III) and $\mathrm{Cf}(\mathrm{III})$ from $1.3 \mathrm{~mol} / \mathrm{L} \mathrm{HNO}_{3}$,

- 4 scrubbing stages for back extraction of the poorly coextracted lanthanides with $0.7 \mathrm{~mol} / \mathrm{L} \mathrm{HNO}_{3}$ and

- 4 stripping stages for the back extraction of the trivalent actinides with $0.5 \mathrm{~mol} / \mathrm{L}$ glycolic acid. The stripping of the extracted trivalent actinides is also thermodynamically possible with diluted nitric acid, but batch experiments showed that the kinetics is rather slow. Therefore, the hydrophilic complexing agent glycolic acid (solution adjusted to $\mathrm{pH} 4$ with $\mathrm{NH}_{3}$ ) was used for stripping [23].

No hydrodynamic problems were encountered during the SANEX test. All of the collected phases were clear and free of entrainment. After the test, all stages (aqueous and organic) and all collected samples, including the samples to determine the transient state, were analysed as described above. The acidity profile was determined for the aqueous phase by potentiometric titration with $\mathrm{NaOH}$ solution.

\section{Results and discussion}

\subsection{Batch studies}

In the reported SANEX process using $\mathrm{CyMe}_{4} \mathrm{BTBP}+$ DMDOHEMA [11] as solvent, a rather high malonamide concentration of $0.25 \mathrm{~mol} / \mathrm{L}$ was used as phase transfer reagent to improve the extraction kinetics of the trivalent actinides into the organic phase. Since DMDOHEMA limits the dissolution of the BTBP to a maximum of $0.015 \mathrm{~mol} / \mathrm{L}$, we investigated whether TODGA is suitable as an alternative phase transfer reagent. Secondly, the amount of TODGA to be used in the new solvent composition could be lower than the amount of DMDOHEMA, thereby reducing the amount of secondary wastes.

Fig. 3 shows the extraction of Am and Eu by a mixture of $0.015 \mathrm{~mol} / \mathrm{L} \mathrm{CyMe}{ }_{4} \mathrm{BTBP}$ and variable TODGA concentrations $(0.005-0.1 \mathrm{~mol} / \mathrm{L})$. It can be seen that a TODGA concentration of $0.05 \mathrm{~mol} / \mathrm{L}$ has an adverse effect on the $\mathrm{Am} / \mathrm{Eu}$ separation factor. The $\mathrm{SF}_{\mathrm{Am} / \mathrm{Eu}}$ decreases from initially 100 (without TODGA) to around 3. This can be explained as TODGA itself is a very efficient extractant for the co-extraction of actinides(III) and lanthanides(III), even at low acidities, but unselective [24].

By decreasing the TODGA concentration in the mixture the reduction of the separation factor is less pronounced. A good compromise regarding solubility of $\mathrm{CyMe}_{4} \mathrm{BTBP}$, Am(III) distribution ratios and kinetics while keeping a high Am/Eu-separation factor of 100 was a mixture of $0.015 \mathrm{~mol} / \mathrm{L} \mathrm{CyMe}{ }_{4} \mathrm{BTBP}+0.005 \mathrm{~mol} / \mathrm{L}$ TODGA in $n$ octanol. The $\mathrm{CyMe}_{4} \mathrm{BTBP}$ and TODGA molecules show high stability against hydrolytic and radiolytic attack and solvents using those extractants show good hydrodynamic behaviour [30-36].

The influence on the extraction time is shown in Fig. 4. It shows that the BTBP alone extracts very slowly. The equilibrium distribution ratios of both $\mathrm{Am}$ and $\mathrm{Eu}$ are attained after approx. $60 \mathrm{~min}$. The addition of small amounts of TODGA, however, significantly improves the kinetics and 10 min were sufficient to reach the equilibrium. The comparison with DMDOHEMA shows that the latter accelerates the extraction even more since only $5 \mathrm{~min}$ are necessary to attain the equilibrium $\mathrm{Am}$ and $\mathrm{Eu}$ distribution ratios.

\subsection{Results of the single centrifuge studies}

Equilibrium batch extraction data are generally used to design flow-sheets. To get an idea of the efficiency of each step (extraction, scrubbing and stripping), a series of singlecentrifuge experiments was carried out. The results from single centrifugal contactor experiments at the flow-rates proposed for the counter-current test, the calculated stageefficiencies (see Eq. 3) and experimental batch equilibrium data are shown in Table 3. The used flow-rates allow a contacting time of the two phases in the mixing chamber of the centrifuges which is still not sufficient to reach the equilibrium, although the flow-rates are at the lower limit of the 

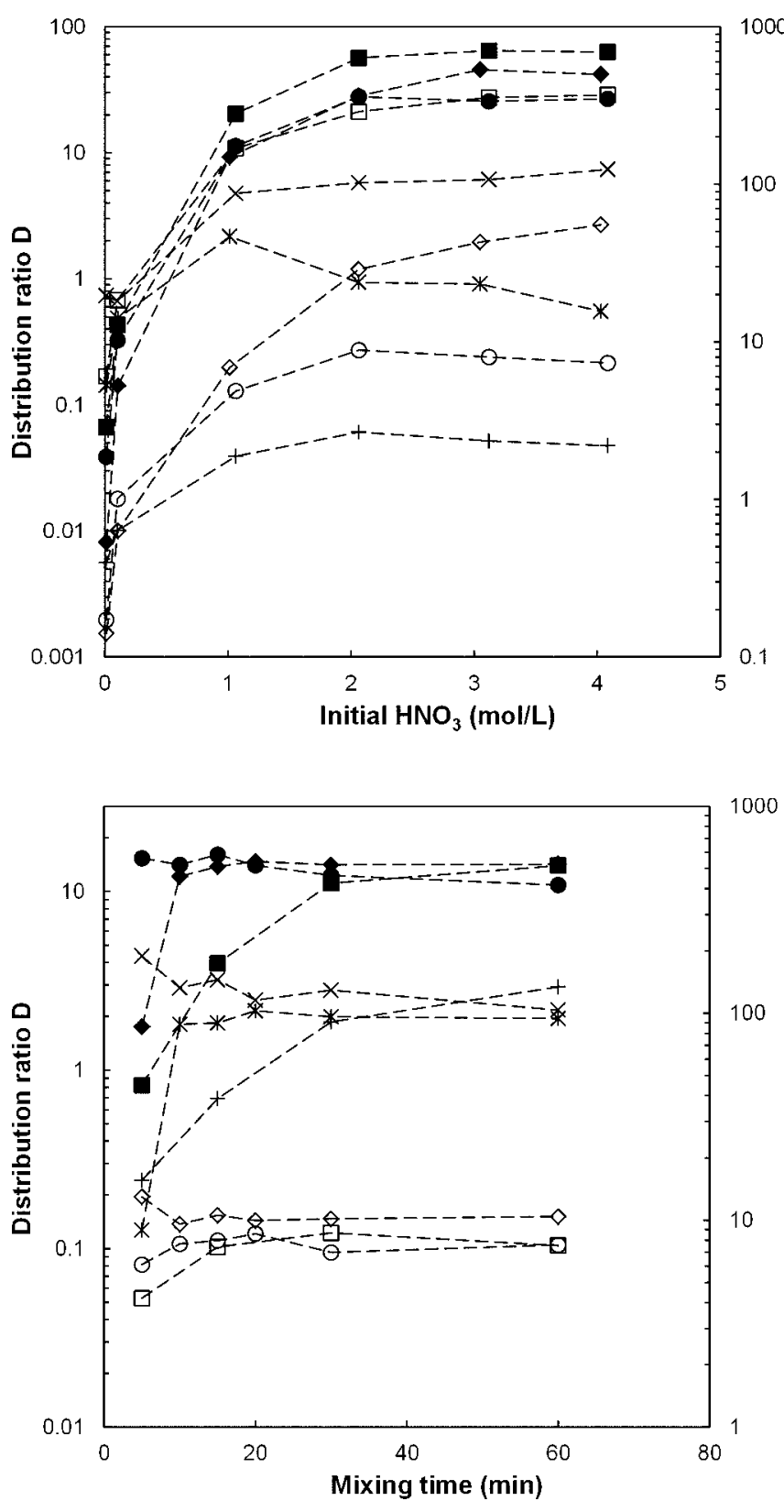

centrifugal contactors operational design. The single-stage distribution ratios are lower (extraction) or higher (scrubbing and stripping) than the respective equilibrium distribution ratios.

$$
E=\frac{C_{\text {feed }}-C_{\text {out }}}{C_{\text {feed }}-C_{\text {Eq }}}
$$

where $E$ is the stage efficiency.

\subsection{Results of the full counter-current test}

The aim of this test was to selectively separate the trivalent actinides from the trivalent lanthanides. The most important results of gamma, alpha and ICP-MS measurements are given in Table 4. The process decontamination factors $\mathrm{DF}_{\mathrm{Am} / \mathrm{Ln}}$ and $\mathrm{DF}_{\text {feed/raff }}$ were calculated according to the following Eqs. (4) and (5), where $Q$ is the flow-rate of the specific phase in $\mathrm{mL} / \mathrm{h}$ and $C$ is the concentration of the element in $\mathrm{mg} / \mathrm{L}$.

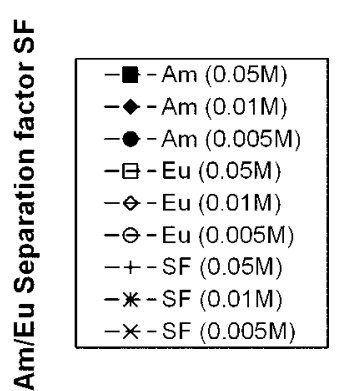

Fig. 3. Extraction of $\mathrm{Am}(\mathrm{III})$ and $\mathrm{Eu}(\mathrm{III})$ with $\mathrm{CyMe}_{4} \mathrm{BTBP}$ as a function of the nitric acid concentration. The influence of variable TODGA concentrations. Organic phase: $0.015 \mathrm{~mol} / \mathrm{L} \mathrm{CyMe}_{4} \mathrm{BTBP}$ + variable TODGA in $n$-octanol (not pre-equilibrated with nitric acid). Aqueous phase: nitric acid + lanthanides $\left(10^{-3} \mathrm{~mol} / \mathrm{L}\right.$ each $)+$ tracers $\left({ }^{241} \mathrm{Am}\right.$, ${ }^{152} \mathrm{Eu},{ }^{244} \mathrm{Cm},{ }^{252} \mathrm{Cf}$ ), mixing time: $60 \mathrm{~min}$; $T=22 \pm 1{ }^{\circ} \mathrm{C}$.

Fig. 4. Influence of the mixing time and different phase transfer agents on the $\mathrm{Am}(\mathrm{III})$ and $\mathrm{Eu}(\mathrm{III})$ extraction with $\mathrm{CyMe}_{4} \mathrm{BTBP}$ from nitric acid. Organic phase: $0.015 \mathrm{~mol} / \mathrm{L} \mathrm{CyMe}_{4} \mathrm{BTBP}$ alone or $+0.005 \mathrm{~mol} / \mathrm{L}$ TODGA or $+0.25 \mathrm{~mol} / \mathrm{L}$ DMDOHEMA in $n$-octanol (not preequilibrated with nitric acid). Aqueous phase: $1.3 \mathrm{~mol} / \mathrm{L}$ nitric acid + lanthanides $\left(10^{-3} \mathrm{~mol} / \mathrm{L}\right.$ each $)+$ tracers $\left({ }^{241} \mathrm{Am}\right.$, ${ }^{152} \mathrm{Eu},{ }^{244} \mathrm{Cm},{ }^{252} \mathrm{Cf}$ ), mixing time: $60 \mathrm{~min}$; $T=22 \pm 1{ }^{\circ} \mathrm{C}$.

$$
\begin{aligned}
& \mathrm{DF}_{\mathrm{Am} / \mathrm{Ln}}=\frac{Q_{\text {feed }} \cdot C_{\mathrm{Ln}, \text { feed }} \cdot C_{\mathrm{Am}, \text { organic product (stage 16) }}}{Q_{\text {organic phase }} \cdot C_{\mathrm{Am}, \text { feed }} \cdot C_{\mathrm{Ln} \text {, organic product (stage 16) }}} \\
& \mathrm{DF}_{\text {feed } / \text { raff }}=\frac{Q_{\text {feed }} \cdot C_{\text {feed }}}{Q_{\text {raff }} \cdot C_{\text {raff }}}
\end{aligned}
$$

The main conclusions drawn from Table 4 can be summarized as follows. The trivalent actinides americium and californium were quantitatively extracted $(>99.9 \%)$ and completely recovered after stripping with glycolic acid. High decontamination factors over 1000 between the feed and the raffinate were achieved for these actinides. Curium was extracted up to $>99.7 \%$, but $0.3 \%$ still remained in the raffinate, so a lower DF of 314 was achieved here. The results of the back extraction showed that 4 stages were sufficient for the actinide(III) stripping as also shown in Fig. 5. However, gamma spectrometric analysis showed that $0.04 \%$ of ${ }^{241} \mathrm{Am}$ was still found in the spent solvent. It can be assumed that the behaviour of $\mathrm{Cm}$ and $\mathrm{Cf}$ is similar, since the 
Table 3. Results of the experimental single centrifugal contactor tests, batch extraction tests and calculated stage efficiencies (see Eq. 3).

\begin{tabular}{|c|c|c|c|c|c|c|c|c|}
\hline $\begin{array}{l}\text { Single centrifuge } \\
\text { test }\end{array}$ & $\begin{array}{c}\text { A/O } \\
\text { flowrates }\end{array}$ & Am, $\gamma$ & $\mathrm{Eu}, \gamma$ & Am, $\alpha$ & $\mathrm{Cm}, \alpha$ & $\mathrm{Cf}, \alpha$ & $\mathrm{SF}_{\mathrm{Am} / \mathrm{Cm}, \alpha}$ & $\mathrm{SF}_{\mathrm{Am} / \mathrm{Eu}, \gamma}$ \\
\hline Extraction $(D)$ & $20 / 10$ & 1.22 & 0.18 & 1.58 & 1.16 & 2.18 & 1.36 & 6.8 \\
\hline Batch/well $(D)^{a}$ & & 17.1 & 0.24 & 17.0 & 10.5 & 128 & 1.62 & 71.3 \\
\hline Stage efficiency $(\%)$ & & 42 & 77 & 49 & 44 & 53 & & \\
\hline Scrubbing $(D)$ & $10 / 10$ & 17.5 & 0.72 & 15.0 & 11.4 & 114 & 1.32 & 24.3 \\
\hline Batch/well $(D)^{a}$ & & 9.91 & 0.18 & 9.04 & 5.73 & 86.4 & 1.58 & 55.1 \\
\hline Stage efficiency (\%) & & 59 & 69 & 63 & 54 & 76 & & \\
\hline Stripping $(D)$ & $10 / 10$ & 0.04 & 0.03 & 0.04 & 0.06 & 0.37 & 1.50 & 1.3 \\
\hline Batch/well $(D)^{a}$ & & $<0.01$ & $<0.01$ & $<0.01$ & $<0.01$ & $<0.01$ & - & - \\
\hline Stage efficiency (\%) & & $>97$ & $>98$ & $>97$ & $>95$ & $>74$ & & \\
\hline Batch tests & Mixing time & $D_{\mathrm{Am}, \gamma}$ & $D_{\mathrm{Eu}, \gamma}$ & $D_{\mathrm{Am}, \alpha}$ & $D_{\mathrm{Cm}, \alpha}$ & $D_{\mathrm{Cf}, \alpha}$ & $\mathrm{SF}_{\mathrm{Am} / \mathrm{Cm}, \alpha}$ & $\mathrm{SF}_{\mathrm{Am} / \mathrm{Eu}, \gamma}$ \\
\hline Extraction & $15 \mathrm{~min}$ & 22.2 & 0.28 & 18.6 & 12.1 & 166 & 1.53 & 79.3 \\
\hline Scrubbing & $15 \min$ & 11.5 & 0.22 & 9.82 & 6.31 & 88.9 & 1.55 & 52.3 \\
\hline Stripping & $15 \mathrm{~min}$ & $<0.01$ & $<0.01$ & $<0.01$ & $<0.01$ & $<0.01$ & - & - \\
\hline
\end{tabular}

a: The content of the mixing chamber and wells was shaken for $15 \mathrm{~min}$ to reach the equilibrium.

Table 4. Main results of the SANEX process test.

\begin{tabular}{|c|c|c|c|c|c|}
\hline Elements & $\begin{array}{l}\% \text { in } \\
\text { raffinate }\end{array}$ & $\begin{array}{c}\% \text { in } \mathrm{An}(\mathrm{III}) \\
\text { prod. } \\
\text { (stage } 17 \mathrm{aq})\end{array}$ & $\begin{array}{l}\% \text { in sol- } \\
\text { vent (stage } \\
20 \text { org) }\end{array}$ & $\begin{array}{c}\text { DF } \\
\text { feed/raff }\end{array}$ & $\begin{array}{c}\mathrm{DF} \\
\mathrm{Am} / \mathrm{Ln}\end{array}$ \\
\hline $\mathrm{Y}$ & $>97$ & 3.22 & 0.0054 & - & 25 \\
\hline $\mathrm{La}$ & $>99.8$ & 0.10 & 0.0015 & - & 41449 \\
\hline $\mathrm{Ce}$ & $>99.8$ & 0.11 & 0.0044 & - & 6184 \\
\hline $\operatorname{Pr}$ & $>99.8$ & 0.11 & 0.0013 & - & 11802 \\
\hline $\mathrm{Nd}$ & $>99.8$ & 0.10 & 0.0007 & - & 14746 \\
\hline $\mathrm{Sm}$ & $>99.7$ & 0.23 & 0.0010 & - & 559 \\
\hline $\mathrm{Eu}$ & $>99.2$ & 0.76 & 0.0018 & - & 102 \\
\hline${ }^{152} \mathrm{Eu}(\gamma)$ & 99.2 & 0.8 & 0.022 & 0.95 & \\
\hline $\mathrm{Gd}$ & $>98$ & 1.62 & 0.0010 & - & 56 \\
\hline${ }^{241} \mathrm{Am}(\gamma)$ & 0.08 & 99.9 & 0.038 & 1161 & \\
\hline${ }^{241} \operatorname{Am}(\alpha)$ & $<$ d.l. & 99.2 & $<$ d.l. & $>1000$ & \\
\hline${ }^{244} \mathrm{Cm}(\alpha)$ & 0.32 & 99.2 & $<$ d.l. & 314 & \\
\hline${ }^{252} \mathrm{Cf}(\alpha)$ & $<$ d.l. & $>99.9$ & $<$ d.l. & $>1000$ & \\
\hline
\end{tabular}

background level of alpha spectrometry was slightly higher than the gamma measurement (Fig. 5). The mass balances were good for the trivalent actinides. For the lanthanides, however, we observed an excess in the raffinate. High decontamination factors were measured between americium, here as a representative of the trivalent actinides, and the lighter lanthanides $\mathrm{La}, \mathrm{Ce}, \mathrm{Pr}$ and $\mathrm{Nd}$. This was in agreement with the results obtained in batch experiments. As shown in Table 4, and Fig. 6, acid scrubbing efficiently reduced the co-extraction of the lighter lanthanides. Since the lighter lanthanides are contained in higher amounts in genuine irradiated fuels, this is a very positive result. The heavier lanthanides $\mathrm{Sm}, \mathrm{Eu}$, and $\mathrm{Gd}$, which are much less concentrated in the feed solution, were transported to the organic phase to a small extent and also back-extracted together with the actinides. The co-extraction of $\mathrm{Gd}(1.6 \%), \mathrm{Eu}(0.8 \%)$, and $\mathrm{Y}(3.2 \%)$ can be further reduced by adding more scrubbing stages. If the total lanthanide inventory is considered, the actinide (III) product stream was only contaminated with less than 0.5 mass- $\%$ of the initial lanthanides. As this test was performed using trace amounts of An, a Ln/An ratio cannot be calculated directly. Assuming an initial total amount of $150 \mathrm{mg} / \mathrm{L} \mathrm{An} \mathrm{(e.g.} \mathrm{from} \mathrm{the} \mathrm{TODGA/TBP} \mathrm{process} \mathrm{[26])}$ the total Ln amount in the MA product would be $4.1 \%$. This is a very good result with respect to the P\&T strategy for minor actinides, which aims to achieve a total lanthanide contamination in the minor actinide product not higher than $5 \%$ [37]. A future hot test using a genuine feed solution will demonstrate the proper feasibility of this process for the P\&T strategy.

Fig. 7 shows the experimental and calculated profiles for ${ }^{241} \mathrm{Am}$ and ${ }^{152} \mathrm{Eu}$. Data from single stage centrifugal contactor experiments were used for the transfer functions.

The extraction of $\mathrm{Am}$ and $\mathrm{Eu}$ are under-estimated by the model while the scrubbing is in good agreement (the scrubbing profiles do not look so good in Fig. 7 since the extraction profile is off). The reason why there is a difference between the calculated and experimental extraction profiles has to be investigated further. The most reasonable explanation is that there was a difference in the metal concentra- 


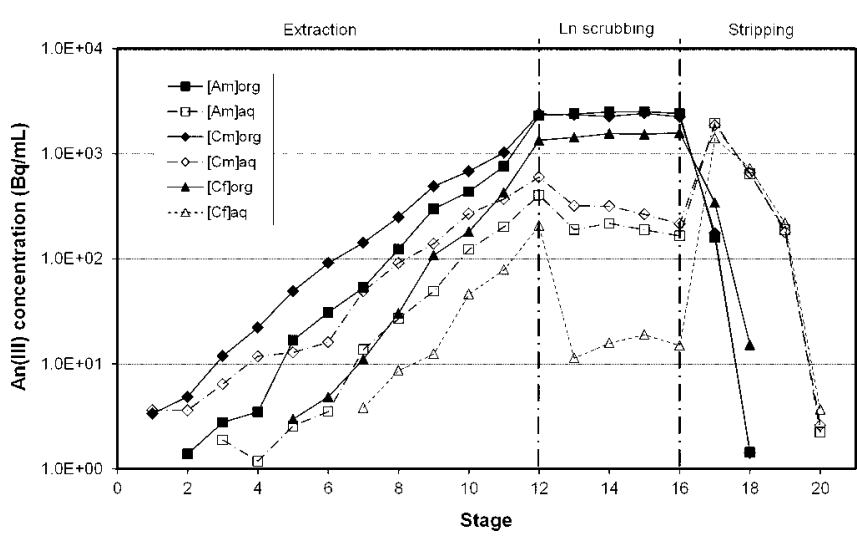

Fig. 5. Experimental organic and aqueous $\mathrm{Am}(\mathrm{III}), \mathrm{Cm}(\mathrm{III})$, and $\mathrm{Cf}(\mathrm{III})$ concentration profiles during the SANEX test.

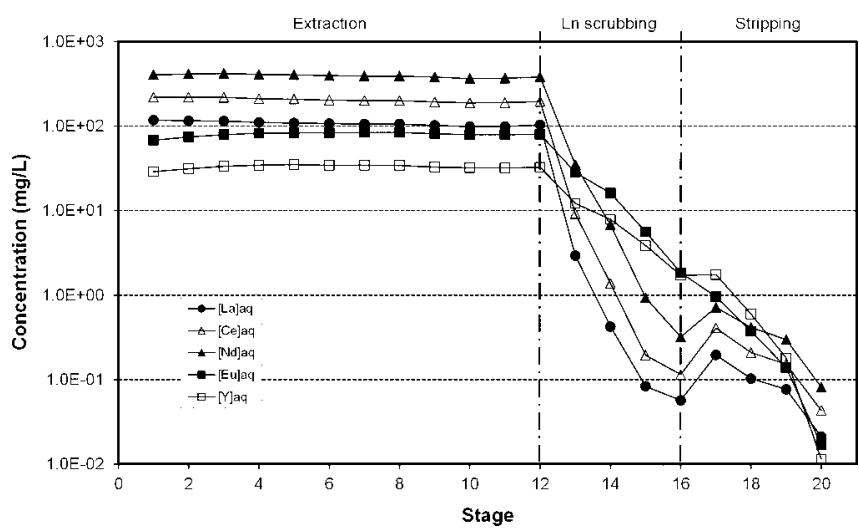

Fig. 6. Experimental aqueous concentration profiles of some lanthanides during the SANEX test.

tions between the single stage and the full test. A change in the loading gives both different equilibrium distribution ratios and different transfer rates due to the change in free ligand concentration. This explanation is also valid for the scrubbing results, since in the scrubbing section the loading is negligible and hence the single stage data agree with the process. Differences in the nitric acid concentration between the single stage and the full test in the extraction section could also be an explanation. The calculated Am profile is, however, conservative. In the stripping section the calculated and experimental values agree for the organic phase until stage 19 for Am (only until stage 17 for Eu), where the experimental concentration is too low to be measured accurately. The calculated aqueous profile only fits for stage 17.

Fig. 8 shows the experimental and calculated profiles where the calculations have been adjusted in the extraction to fit the experimental data (the scrub fits automatically better when the extraction profile is corrected). For Am a higher transfer rate had to be used in the extraction section compared to the calculations using single stage kinetics. With a B-value (Eq. 2) about two times higher for the extraction stages, the calculated profile fitted the experimental profile with good agreement. It was not possible to fit the stripping section to the experimental data.

For Eu, a higher equilibrium distribution ratio, compared to the single stage experiment, had to be used to fit the extraction profile. In the extraction section the distribution ratio should be close to the equilibrium, so an average value

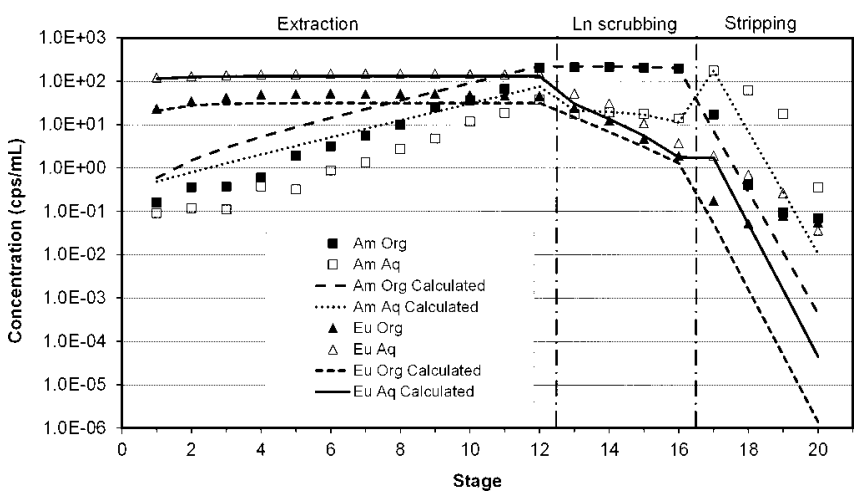

Fig. 7. Experimental and calculated profiles for ${ }^{241} \mathrm{Am}$ and ${ }^{152} \mathrm{Eu}$.

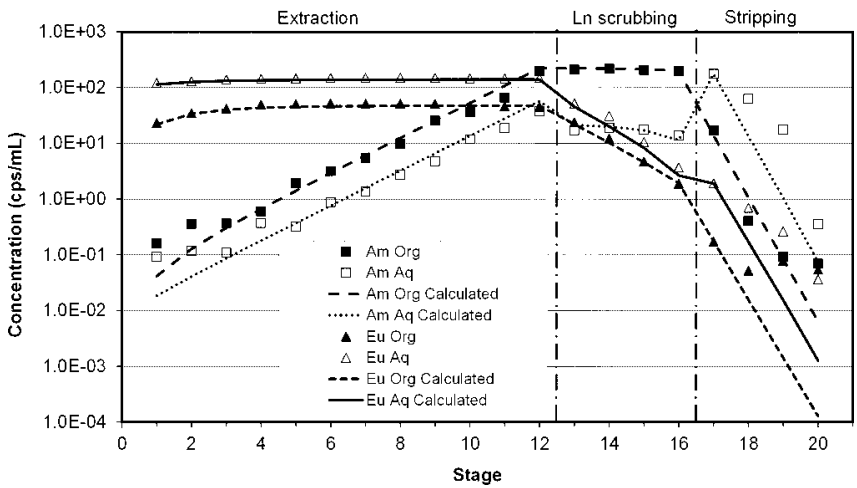

Fig. 8. Experimental and fitted profiles for ${ }^{241} \mathrm{Am}$ and ${ }^{152} \mathrm{Eu}$.

of $D_{\mathrm{Eq}}=0.34$ from stage 3-11 was used (the distribution ratio differs from the equilibrium value in the first two and last stages). The transfer rate was calculated using the distribution ratio from stage 1 as a single stage value (this could not be done for Am due to too low concentrations). As for Am, the stripping section could not be described well by the model.

\section{Conclusions}

The results of the spiked multi-stage counter-current centrifugal contactor test showed that the mixture of $\mathrm{CyMe}_{4} \mathrm{BTBP}$ and TODGA in $n$-octanol is a promising solvent for the selective separation of trivalent actinides from trivalent lanthanides from a rather acidic solution of $1.3 \mathrm{~mol} / \mathrm{L} \mathrm{HNO}_{3}$. This was demonstrated in an optimised 20-stage flow-sheet. More than $99.9 \%$ of the trivalent actinides were extracted from the feed solution and stripped back to the aqueous product fraction. The actinide(III) product stream was contaminated with less than 0.5 mass- $\%$ of the initial lanthanides, so that the ambitious goal of $<5 \%$ was achieved. Considering the slow extraction kinetics and thereby low efficiency of the extraction stages, the experimental results are in good agreement with the calculations, taking into account the slow kinetics.

Acknowledgment. Financial support from the European Commission is acknowledged (ACSEPT is a Collaborative Project of the EC FP7Euratom, no. FP7-CP-2007-211 267). The authors would like to thank Dr. Mark Foreman, Chalmers University, Sweden, and Dr. M. J. Hudson, University of Reading, UK, for providing the BTBP. 


\section{References}

1. Actinide and Fission Product Partitioning and Transmutation Status and Assessment Report. OECD-NEA, Paris, France (1999).

2. Madic, C., Hudson, M. J., Liljenzin, J. O., Glatz, J. P., Nannicini, R., Facchini, A., Kolarik, Z., Odoj, R.: New partitioning techniques for minor actinides. European Commission, Luxembourg (2000).

3. Madic, C., Testard, F., Hudson, M. J., Liljenzin, J. O., Christiansen, B., Ferrando, M., Facchini, A., Geist, A., Modolo, G., Gonzales-Esperanto, A., Mendoza, J. D.: PARTNEW - New Solvent Extraction Processes for Minor Actinides - Final Report, CEA-report 6066 (2004).

4. Madic, C., Hudson, M. J., Baron, P., Ouvrier, N., Hill, C., Arnaud, F., Espartero, A. G., Desreux, J.-F., Modolo, G., Malmbeck, R., Bourg, S., De Angelis, G., Uhlir, J.: Proceedings of FISA, Luxembourg (2006).

5. Madic, C., Hudson, M. J., Liljenzin, J.-O., Glatz, J.-P., Nannicini, R., Facchini, A., Kolarik, Z., Odoj, R.: Prog. Nucl. Energy 40(3-4), 523-526 (2002).

6. Serrano-Purroy, D., Baron, P., Christiansen, B., Malmbeck, R. Sorel, C., Glatz, J. P.: Radiochim. Acta 93(6), 351-355 (2005).

7. Modolo, G., Asp, H., Schreinemachers, C., Vijgen, H.: Solvent Extr. Ion Exch. 25(6), 703-721 (2007).

8. Modolo, G., Asp, H., Vijgen, H., Malmbeck, R., Magnusson, D., Sorel, C.: Solvent Extr. Ion Exch. 26(1), 62-76 (2008).

9. Gujar, R. B., Ansari, S. A., Prabhu, D. R., Raut, D. R., Pathak, P. N., Sengupta, A., Thulasidas, S. K., Mohapatra, P. K., Manchanda, V. K.: Solvent Extr. Ion Exch. 28(6), 764-777 (2010).

10. Gujar, R. B., Ansari, S. A., Mohapatra, P. K., Manchanda, V. K.: Solvent Extr. Ion Exch. 28(3), 350-366 (2010).

11. Magnusson, D., Christiansen, B., Foreman, M. R. S., Geist, A., Glatz, J. P., Malmbeck, R., Modolo, G., Serrano-Purroy, D., Sorel, C.: Solvent Extr. Ion Exch. 27(2), 97-106 (2009).

12. Nash, K. L., Madic, C., Mathur, J. N., Lacquement, J.: Actinide separation science and technology. In: The Chemistry of Actinide and Transactinide Elements. Chapt. 24, $3^{\text {rd }}$ Edn. (Morss, L. R., Edelstein, N. M., Fuger, J., Katz, J. J., eds.), Springer, Dordrecht, The Netherlands (2006), pp. 2622-2798.

13. Hill, C.: Overview of recent advances in An(III)/Ln(III) separation by solvent extraction. In: Ion Exchange and Solvent Extraction, A Series of Advances. Vol. 19, Chapt. 3 (Moyer, B. A., ed.) CRC Taylor and Francis, Boca Raton, FL (2009), pp. 119193.

14. Achuthan, P. V., Janardanan, C.: J. Radioanal. Nucl. Chem. 287(3), 753-759 (2011).

15. Mincher, B. J., Schmitt, N. C., Case, M. E.: Solvent Extr. Ion Exch. 29(2), 247-259 (2011).

16. Peterman, D. R., Greenhalgh, M. R., Tillotson, R. D., Klaehn, J. R., Harrup, M. K., Luther, T. A., Law, J. D.: Sep. Sci. Technol. 45(12), 1711-1717 (2010)
17. Lumetta, G. J., Gelis, A. V., Vandegrift, G. F.: Solvent Extr. Ion Exch. 28(3), 287-312 (2010).

18. Nilsson, M., Nash, K. L.: Solvent Extr. Ion Exch. 25(6), 665-701 (2007).

19. Ishimori, K., Watanabe, M., Kimura, T., Yaita, T., Yamada, T., Kataoka, Y., Shinoda, S., Tsukube, H.: Chem. Lett. 34(8), 1112 1113 (2005).

20. Kolarik, Z.: Solvent Extr. Ion Exch. 21(3), 381-397 (2003).

21. Hill, C., Guillaneux, D., Berthon, L., Madic, C.: J. Nucl. Sci. Technol. Suppl. 3, 309-312 (2002).

22. Foreman, M. R. S., Hudson, M. J., Drew, M. G. B., Hill, C., Madic, C.: Dalton Trans. 13, 1645-1653 (2006).

23. Geist, A., Hill, C., Modolo, G., Foreman, M. R. S. J., Weigl, M., Gompper, K., Hudson, M. J., Madic, C.: Solvent Extr. Ion Exch. 24(4), 463-483 (2006).

24. Sasaki, Y., Sugo, Y., Suzuki, S., Tachimori, S.: Solvent Extr. Ion Exch. 19(1), 91-103 (2001).

25. Magnusson, D., Malmbeck, R.: Solvent Extr. Ion Exch. 30(2), 115-126 (2012).

26. Magnusson, D., Christiansen, B., Glatz, J.-P., Malmbeck, R., Modolo, G., Serrano-Purroy, D., Sorel, C.: Solvent Extr. Ion Exch. 27(1), 26-35 (2009).

27. Schulz, W. W., Horwitz, E. P.: Separ. Sci. Technol. 23(12-13), 1191-1210 (1988).

28. Dinh, B., Mauborgne, B., Baron, P., Dynamic simulation of extraction operations. Applications in nuclear fuel reprocessing. In: European Symposium on Computer Aided Process Engineering-2, ESCAPE2. Toulouse, France, 1992.

29. Magnusson, D., Christiansen, B., Glatz, J.-P., Malmbeck, R., Modolo, G., Serrano-Purroy, D., Sorel, C.: Radiochim. Acta 97(3), 155-159 (2009).

30. Mincher, B. J., Modolo, G., Mezyk, S. P.: Solvent Extr. Ion Exch. 27(5/6), 579-606 (2009)

31. Mincher, B. J., Modolo, G., Mezyk, S. P.: Solvent Extr. Ion Exch. 27(1), 1-25 (2009).

32. Mincher, B. J., Modolo, G., Mezyk, S. P.: Solvent Extr. Ion Exch. 27(3), 331-353 (2009).

33. Gujar, R. B., Ansari, S. A., Bhattacharyya, A., Kanekar, A. S., Pathak, P. N., Mohapatra, P. K., Manchanda, V. K.: Solvent Extr. Ion Exch. 30(3), 278-290 (2012).

34. Aneheim, E., Ekberg, C., Fermvik, A., Foreman, M. R. S. J., Grúner, B., Hájková, Z., Kvičalová, M.: Solvent Extr. Ion Exch. 29(2), 157-175 (2011).

35. Magnusson, D., Christiansen, B., Malmbeck, R., Glatz, J. P.: Radiochim. Acta 97(9), 497-502 (2009).

36. Fermvik, A., Ekberg, C., Englund, S., Foreman, M. R. S. J., Modolo, G., Retegan, T., Skarnemark, G.: Radiochim. Acta 97(6), 319-324 (2009).

37. Implications of Partitioning and Transmutation in Radioactive Waste Management. Vol. 435, Technical Report Series No. 435, International Atomic Energy Agency, Vienna, Austria, (2004). 